\title{
Fresh Osteochondral Allograft Transplantation for Fractures of the Knee
}

CARTILAGE

2017, Vol. 8(2) |55-16|

(c) The Author(s) 2016

Reprints and permissions:

sagepub.com/journalsPermissions.nav

DOI: $10.1177 / 1947603516657640$

journals.sagepub.com/home/CAR

@SAGE

\author{
Guilherme C. Gracitelli', Luis Eduardo Passarelli Tirico ${ }^{2}$, Julie C. McCauley ${ }^{3}$, \\ Pamela A. Pulido ${ }^{3}$, and William D. Bugbee ${ }^{4}$
}

\begin{abstract}
Objective: The purpose of this study was to evaluate functional outcomes and allograft survivorship among patients with knee fracture who underwent fresh osteochondral allograft (OCA) transplantation as a salvage treatment option. Design: Retrospective analysis of prospectively collected data. Setting: Department of Orthopaedic Surgery at one hospital. Patients: Fresh OCAs were implanted for osteochondral lesions after knee fracture in 24 males and 15 females with an average age of 34 years. Twenty-nine lesions (74\%) were tibial plateau fractures, $6(15 \%)$ were femoral condyle fractures, and 4 (10\%) were patella fractures. Main Outcome Measurements: Clinical evaluation included modified Merle d'Aubigné-Postel (18-point), International Knee Documentation Committee, and Knee Society function scores, and patient satisfaction. Failure of OCA was defined as revision OCA or conversion to total knee arthroplasty (TKA). Results: Nineteen of 39 knees (49\%) had further surgery. Ten knees (26\%) were considered OCA failures (3 OCA revisions, 6 TKA, and I patellectomy). Survivorship of the OCA was $82.6 \%$ at 5 years and $69.6 \%$ at 10 years. Among the 29 knees $(74 \%)$ that had the OCA still in situ, median follow-up was 6.6 years. Pain and function improved from preoperative to latest follow-up; $83 \%$ of patients reported satisfaction with OCA results. Conclusion: OCA transplantation is a useful salvage treatment option for osteochondral lesions caused by knee fracture. Although the reoperation rate was high, successful outcome was associated with significant clinical improvement.
\end{abstract}

\section{Keywords}

osteochondral allograft transplant, knee fracture, functional outcomes, survivorship

\section{Introduction}

Fresh osteochondral allograft (OCA) transplantation has been used for the treatment of osteochondral defects for many decades. The first report of this technique was done by Lexer in $1908^{1}$ treating knee anchylosis with allografts from fresh amputated limbs. Gross and colleagues ${ }^{2}$ popularized the procedure for the treatment of osteoarthritis and large bone defects after oncologic ressection. ${ }^{3}$ Since then, many authors have reported their results with this technique for the treatment of many pathologies in the knee joint such as osteochondritis dissecans, femoral and tibial posttraumatic defects, secondary osteonecrosis, and early degenerative disease. ${ }^{4-14}$

Displaced intraarticular fractures require open reduction and internal fixation; however, the desired anatomical reduction may not be achieved due to bone stock loss or surgical technical errors leading to malunion. Moreover, the exertion of the trauma acting on the cartilage surface can lead to the death of chondrocytes, subchondral bone damage, and failure of the osteochondral unit. Cartilage repair techniques such as debridement, microfracture, and osteochondral autograft transplantation have limited indication in posttraumatic defects in the knee because they are ideally indicated for lesions smaller than $4 \mathrm{~cm}^{2}$ and $10 \mathrm{~mm}$ in depth. ${ }^{15-17}$ Autologous chondrocyte implantation (ACI) promotes hyaline-like cartilage repair and has shown good results for the treatment of large chondral and osteochondral lesions. ${ }^{18-22}$ ACI has limited indication for uncontained structural osteochondral lesions, and recently ACI has shown higher failure rate after a previous cartilage surgery with subchondral bone damage. ${ }^{23,24}$ Gracitelli et $a l^{25}$ reported that OCA transplantation survivorship and functional outcomes are not affected by previous cartilage repair procedure with subchondral bone damage. Fresh OCAs for the treatment of posttraumatic

\footnotetext{
'Department of Orthopaedic Surgery, Federal University of São Paulo, São Paulo, Brazil

${ }^{2}$ Department of Orthopaedic Surgery, Faculty of Medicine, University of São Paulo, São Paulo, Brazil

${ }^{3}$ Shiley Center for Orthopaedic Research and Education at Scripps Clinic, La Jolla, CA, USA

${ }^{4}$ Division of Orthopaedic Surgery, Scripps Clinic, La Jolla, CA, USA

Corresponding Author:

William D. Bugbee, Division of Orthopaedic Surgery, Scripps Clinic, 10666 North Torrey Pines Rd. MS I 16, La Jolla, CA 92037, USA.

Email: bugbee.william@scrippshealth.org
} 
defects of the knee have been shown to restore the osteochondral unit and have good or excellent objective and subjective outcomes in long-term follow-up. ${ }^{26-31}$ No previous study has addressed the use of OCA transplantation in the long term in different knee fracture locations. The purpose of the present study was to evaluate functional outcomes and survivorship of OCA transplantation among patients with knee fractures who were eligible for OCA transplantation as a salvage treatment option.

\section{Methods}

\section{Patients}

Our institutional review board-approved OCA database, which obtains patient consent to use data, was used to identify 44 patients (44 knees) who underwent OCA for osteochondral lesions after knee fracture from 1986 to 2011. Five patients ( 5 knees) had less than 2 years of follow-up and were excluded. The remaining 39 patients ( 39 knees) comprised the study population, including 24 males and 15 females with an average age of 34 years (range $=16-54$ years). The mean body mass index was $28.4($ range $=19.6-42.1)$.

Indications for the procedure were large osteochondral traumatic lesions due to fractures on the knee. Twenty-nine lesions $(74.3 \%)$ were tibial plateau fractures, $6(15 \%)$ were femoral condyle fractures, and $4(10 \%)$ were patella fractures. Thirty-six knees $(92.3 \%)$ had an average of 2.6 previous surgeries (range $=1-9$ ), including open reduction internal fixation (31), implant removal (screw and/or plate) (14), chondral debridement (19), loose body removal (5), autologous bone grafting (4), bone allografts (4), medial meniscectomies (3), ligament reconstruction (2), subchondral marrow stimulation (2), osteotomies (2), and 7 other previous surgeries (lateral meniscectomy, extensor mechanism surgery, external fixation, external fixation and fasciotomy, incision and drainage, incision and drainage of abscess, partial patellectomy, one of each). The remaining 3 knees had no previous surgeries.

\section{Procedure}

Donor and recipient were paired using the mediolateral width of the proximal tibia of the recipient, in an anteroposterior standing radiograph corrected for magnification, and matched for the direct measurement of the tibial plateau of the donor using a caliper. No blood or human leucocyte antigen typing was performed and no immunosuppressive therapy was used. Fresh OCAs were obtained from donors aged 15 to 40 years who met the criteria of the American Association of Tissue Banks. ${ }^{32}$ All donor tissue was recovered within 24 hours of donor death and was processed and stored fresh at $4^{\circ} \mathrm{C}$ in a tissue culture media until the time of transplantation.
Surgical procedures (Fig. 1) were performed using a full or mini-arthrotomy through a midline incision on the knee joint. Dowel technique with utilization of manufactured instruments was done in 2 patients $(5.1 \%)$, shell technique with free-hand preparation of the grafts in 33 patients $(84.6 \%)$, and combined dowel + shell techniques in 4 patients $(10.3 \%) .{ }^{4,33,34}$ Donor graft was utilized matching the anatomical area of the recipient, trying to preserve as much of the native bone as possible. Pulse lavage was used in all cases to decrease immunologic response to marrow elements in the bone portion. For shell grafts, a maximum of a $2 \mathrm{~mm}$ difference in size was accepted between donor and recipient. Additional fixation was utilized when needed, consisting of bioabsorbable (Chondral Dart; Arthrex, Naples, FL) and/or metal screws. One graft was transplanted in 30 patients $(76.9 \%), 2$ grafts in 8 patients $(20.5 \%)$, and 3 grafts in only 1 patient (2.6\%). Twenty-nine tibial plateau shell grafts (23 lateral and 6 medial) were transplanted, of which 17 were isolated tibial plateaus (56.4\%) and 12 (43.6\%) received a concomitant meniscal allograft (8 lateral and 4 medial).

\section{Evaluations}

Clinical evaluation preoperatively and at each postoperative visit included the modified Merle d'Aubigné-Postel (18point) score $^{8,35}$; International Knee Documentation Committee (IKDC) pain, function, and total $\operatorname{scores}^{36}$; and Knee Society function (KS-F) score. ${ }^{37}$ Scores collected at the most recent follow-up were used for the present study. Patient satisfaction with the procedure was assessed at latest follow-up using a 5-point scale with descriptors from "extremely satisfied" to "extremely dissatisfied." The number and type of further surgery on the operative knee was captured. Failure of the OCA was defined as revision OCA or conversion to arthroplasty. A survival analysis was calculated using the failure as endpoint. Patients who could not return for a postoperative evaluation in person were contacted via telephone or mail.

\section{Statistics}

Means and frequencies were calculated to describe demographic data, details regarding the allograft, number and type of further surgeries after the OCA transplantation, and patient satisfaction at latest follow-up. The Kaplan-Meier method was used to calculate allograft survivorship with graft failure (revision of the graft or conversion to arthroplasty) as the endpoint. The Wilcoxon signed rank test was used to assess change from preoperative to latest follow-up on the modified Merle d'Aubigné-Postel score; IKDC pain, function, and total scores; and KS-F score. The aforementioned analyses were also performed on the subgroup of 29 knees that underwent OCA transplantation exclusively for a 

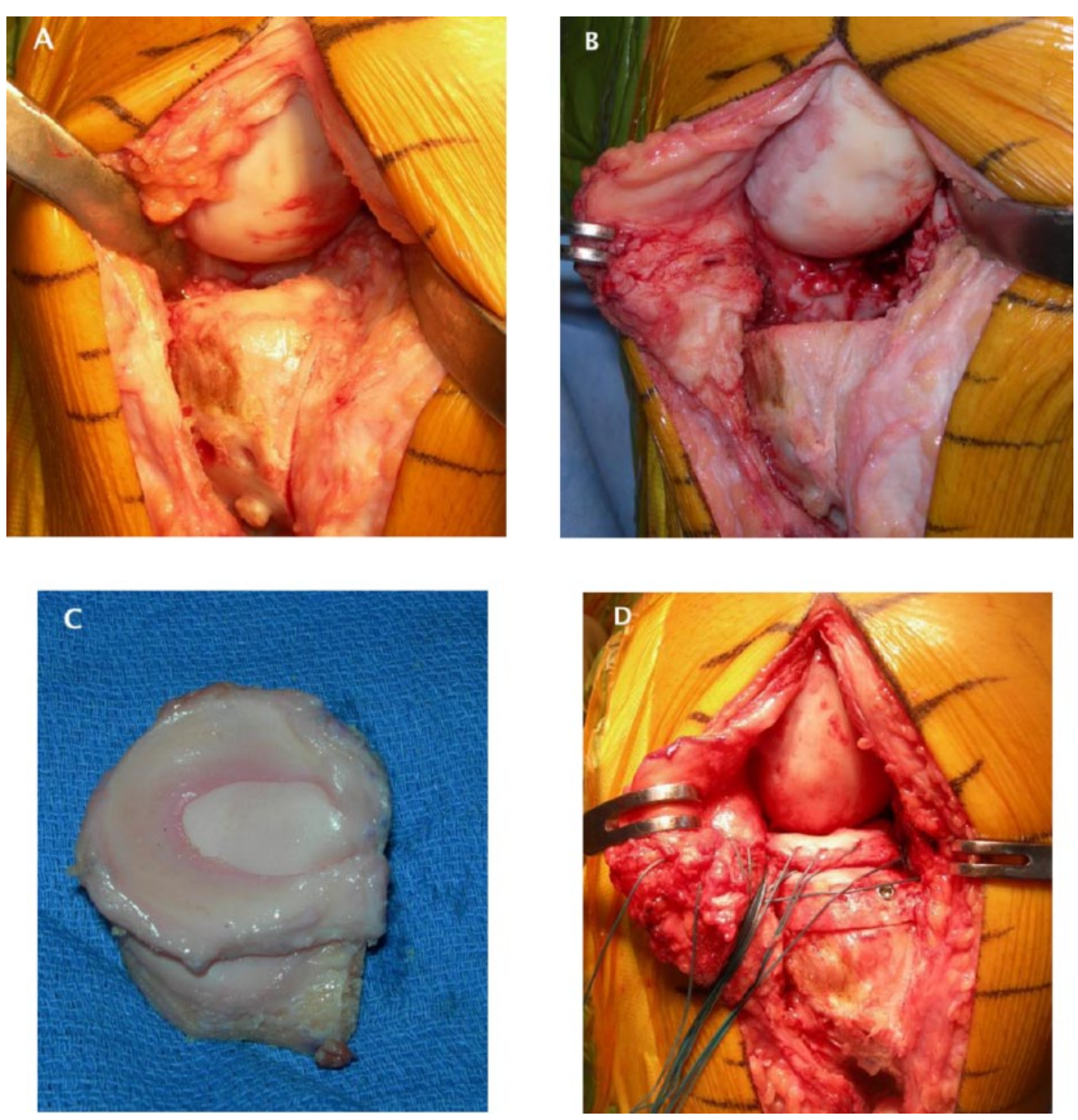

Figure I. Intraoperative images of a knee with tibial plateau fracture. (A) Surgical exposure of the tibial plateau with meniscal and osteochondral lesions. (B) Surgical aspect after tibial plateau cut. (C) Osteochondral allograft of a hemiplateau with the attached meniscus. (D) Final aspect after fixation with 2 cannulated screws and meniscus sutures preparation.

fracture of the tibial plateau. A $P$ value of 0.05 was used to determine statistical significance. SPSS version 13.0 was used for all analyses (IBM Corp, Armonk, NY).

\section{Results}

Patients' demographic data (age, sex, body mass index, fracture location, number of previous surgeries) and allograft details (number of grafts, graft type, and total graft area) were recorded (Table 1), as well as concomitant surgeries with OCA transplantation (Table 2).

Following the OCA transplantation, 19 of 39 knees (49\%) had further surgery (Table 3); of these, 10 knees (26\%) were considered OCA failures (3 OCA revisions, 6 total knee arthroplasties, and 1 patellectomy). Survivorship of the OCA was $82.6 \%$ at 5 years and $69.6 \%$ at 10 years (Fig. 2).

Among the 29 knees (74\%) whose OCA was still in situ, the median follow-up duration was 6.6 years (range $=2-23.6$ years).
Scores on the modified Merle d'Aubigné-Postel, IKDC, and KS-F improved from the preoperative visit to latest follow-up (Table 4); all measures except the IKDC pain were statistically significant. Eighty-three percent of patients reported satisfaction (either satisfied or extremely satisfied) with the results of the OCA transplantation.

A subgroup analysis of 29 knees that underwent OCA transplantation for a fracture of the tibial plateau was performed. Thirteen of the 29 knees (45\%) had further surgery, of which 6 were classified as an OCA failure (1 revision OCA and 5 total knee arthroplasties). Survivorship of the OCA for tibial plateau fractures was $85.8 \%$ at 5 years and $66.8 \%$ at 10 years (Fig. 2). Among the 23 knees that had the OCA in situ, the median follow-up time was 5.8 years (range $=1.9-23.6$ years). Scores on the modified Merle d'Aubigné-Postel (18-point), IKDC, and KS-F improved from the preoperative visit to latest follow-up (Table 5). Similar to the entire cohort, all improvements were statistically significant except for the IKDC pain score. 
Table I. Patient Characteristics and Allograft Details.

\begin{tabular}{lc}
\hline Age, years, mean (range) & $34.7(16-54)$ \\
Sex, $n$ (\%) & \\
Male & $24(61.5 \%)$ \\
Female & $15(38.5 \%)$ \\
Body mass index, mean (range) & $28.3(19-42)$ \\
Fracture location, $n$ (\%) & \\
Lateral tibial plateau & $23(59 \%)$ \\
Medial tibial plateau & $6(15.4 \%)$ \\
Lateral femoral condyle & $5(12.8 \%)$ \\
Medial femoral condyle & $1(2.6 \%)$ \\
Patella & $4(10.3 \%)$ \\
Previous surgery on affected joint, $n(\%)$ & $36(92.3 \%)$ \\
Number of grafts, $n$ (\%) & \\
I & $30(76.9)$ \\
2 & $8(20.5)$ \\
3 & $1(2.6)$ \\
Graft type, $n$ (\%) & \\
Dowel & $2(5.1 \%)$ \\
Shell & $33(84.6 \%)$ \\
Dowel and Shell & $4(10.3 \%)$ \\
Meniscal allograft, $n$ (\%) & $12(30.8 \%)$ \\
Total graft area, cm ${ }^{2}$, mean (range) & $14.5(2-33)$ \\
\hline
\end{tabular}

Table 2. Concomitant Procedures.

\begin{tabular}{lc}
\hline Concomitant Procedure & $n$ \\
\hline Implant removal (screw and/or plate) & 12 \\
Lateral release & 3 \\
Meniscectomy & 3 \\
Distal femoral osteotomy & 2 \\
High tibial osteotomy & $\mathrm{I}$ \\
Synovectomy & $\mathrm{I}$ \\
Epiphysiodesis & $\mathrm{I}$ \\
\hline
\end{tabular}

\section{Discussion}

In this study, overall survivorship of the allograft was $82.6 \%$ at 5 years and $69.6 \%$ at 10 years. Ten knees $(25.6 \%)$ were considered to have allograft failure. Patients who retained their grafts in situ had significant improvement in knee function postoperatively, although $9(23 \%)$ patients required further surgeries.

Fresh OCAs are used in a variety of pathologies affecting the knee joint, such as osteochondritis dissecans, secondary osteonecrosis, osteochondral injuries, and posttraumatic defects. ${ }^{38}$ The concept of this treatment is to provide a biological repair for an osteochondral lesion in young and active patients in an effort to postpone a total joint replacement in young and active adults, such as the patients presented in this cohort.

Large fresh OCAs have been used for the treatment of osteochondral defects in the knee following fractures for
Table 3. Reoperations.

\begin{tabular}{|c|c|}
\hline Procedure & $n$ \\
\hline Diagnostic scope & 3 \\
\hline Implant removal (screw and/or plate) & 3 \\
\hline Loose body removal & $\mathrm{I}$ \\
\hline Incision and drainage & I \\
\hline Osteotomy & I \\
\hline Converted to total or partial arthroplasty ${ }^{\mathrm{a}}$ & 6 \\
\hline OCA revision ${ }^{\mathrm{a}}$ & 3 \\
\hline Patellectomy after traumatic fall ${ }^{\mathrm{a}}$ & I \\
\hline
\end{tabular}

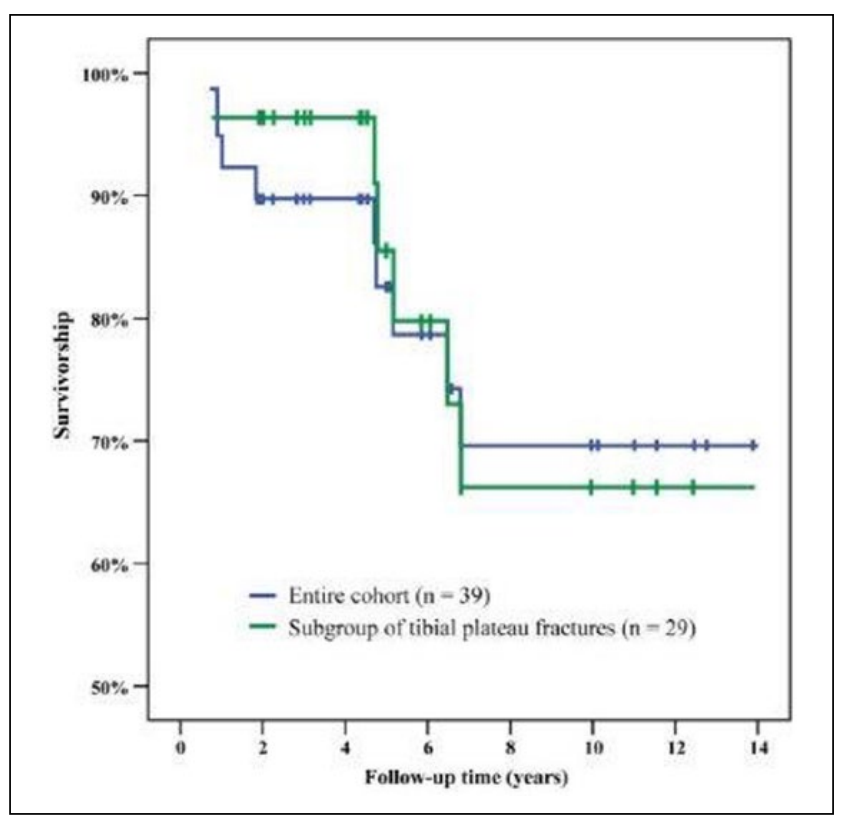

Figure 2. Survivorship of the OCA transplantation with revision of the allograft or conversion to arthroplasty as the endpoint. OCA = osteochondral allograft.

many decades with good results. Many studies with fresh allografts for the treatment of fractures in the knee are case reports or a small case series, showing good results over time..$^{39,40}$ Meyers et $a l^{41}$ in 1989 reported on a series of 40 knees (39 patients) with 11 cases of allografts for tibial plateau fractures and 3 cases for fractures on femoral condyle. Of those, 10 patients were followed with 9 patients scoring excellent and good and only 1 patient with a fair score.

The only series with long-term follow-up reported in the literature, to our knowledge, is from Gross et al. ${ }^{42}$ who evaluated long-term follow-up of fresh allografts for tibial plateau posttraumatic defects and found a survivorship of $95 \%$ at 5 years, $80 \%$ at 10 years, $65 \%$ at 15 years, and $46 \%$ at 20 years. In their series, osteotomies were performed in 
Table 4. Pain and Function among Knees with Grafts In Situ at Latest Follow-Up $(N=29)$.

\begin{tabular}{|c|c|c|c|}
\hline Measure & Preoperative & Postoperative & $P$ \\
\hline $\begin{array}{l}\text { Modified Merle } \\
\text { d'Aubigné-Postel } \\
\text { (I8-point) }\end{array}$ & $11.3 \pm 1.6$ & $14.6 \pm 2.8$ & $<0.001$ \\
\hline Excellent (I8 points) & - & $5(18.5 \%)$ & \\
\hline $\begin{array}{l}\text { Good (15-17 } \\
\text { points) }\end{array}$ & I (3.7\%) & $12(44.4 \%)$ & \\
\hline Fair (12-14 points) & $12(44.4 \%)$ & $6(22.2 \%)$ & \\
\hline Poor (<12 points) & 14 (5।.9\%) & $4(14.8 \%)$ & \\
\hline IKDC pain & $6.4 \pm 2.3$ & $4.5 \pm 3.1$ & 0.055 \\
\hline IKDC function & $2.8 \pm 2.0$ & $6.0 \pm 2.6$ & 0.001 \\
\hline IKDC total & $32.9 \pm 16.6$ & $54.3 \pm 26.0$ & 0.012 \\
\hline $\mathrm{KS}-\mathrm{F}$ & $56.1 \pm 23.9$ & $73.1 \pm 21.5$ & 0.003 \\
\hline
\end{tabular}

Results are shown as mean \pm standard deviation or $n(\%)$. IKDC = International Knee Documentation Committee; KS-F = Knee Society function.

Table 5. Pain and Function among the Subgroup of Knees Presenting with Tibial Plateau Fractures That Had the Allograft In Situ at Latest Follow-Up $(n=23)$.

\begin{tabular}{lccc}
\hline Measure & Preoperative & Postoperative & $P$ \\
\hline $\begin{array}{l}\text { Modified Merle } \\
\text { d'Aubigné and Postel }\end{array}$ & $\mathrm{II} .3 \pm 1.7$ & $14.5 \pm 2.7$ & $0.00 \mathrm{I}$ \\
$\quad$ (I8-point) & & & \\
$\quad$ Excellent (I8 points) & - & $3(15.8 \%)$ & \\
Good (I5-I7 points) & $\mathrm{I}(5.3 \%)$ & $8(42.1 \%)$ & \\
Fair (I2-I4 points) & $8(42.1 \%)$ & $5(26.3 \%)$ & \\
Poor (<12 points) & $10(52.6)$ & $3(15.8 \%)$ & \\
IKDC pain & $6.2 \pm 2.0$ & $4.6 \pm 3.2$ & $0.11 \mathrm{I}$ \\
IKDC function & $2.6 \pm 1.9$ & $5.3 \pm 2.5$ & 0.005 \\
IKDC total & $31.4 \pm 12.6$ & $48.8 \pm 23.8$ & 0.012 \\
KS-F & $51.8 \pm 23.7$ & $71.7 \pm 20.0$ & 0.007 \\
\hline
\end{tabular}

Results are shown as mean \pm standard deviation or $n$ (\%). IKDC = International Knee Documentation Committee; KS-F = Knee Society function.

$58 \%$ of the cases, overcorrecting the mechanical axis in $32 \%$ of the patients.

Getgood et $a l^{43}$ reported the largest series of combined osteochondral and meniscal allograft transplantation. Only 12 patients $(25 \%)$ had knee fracture as the cause of osteochondral lesion. Twenty-six of 48 patients $(54.2 \%)$ needed reoperation, but only 11 patients $(22.9 \%)$ were noted to have failed. Six of the failures were in the osteoarthritic group and 1 was an osteochondritis dissecans lesion group, where bipolar grafts were used. Clinical failures requiring graft removal were more common in the osteoarthritis group and in patients with bipolar grafts. In our study, overall survival of allografts for fractures was $82.6 \%$ at 5 years and $69.6 \%$ at 10 years, with similar outcomes as a previous study. ${ }^{42}$ However, in our series, we only performed 3 osteotomies (12.5\%) concurrently with the allograft transplantation, and only 2 patients underwent an osteotomy before the allograft procedure $(8.3 \%)$. These data show that despite the fact that realignment of the limb is crucial for unloading the affected compartment, the osteochondral fresh allograft is of extreme importance for the success of this procedure.

In the present study, 10 knees $(25.6 \%)$ were considered to have allograft failure and 9 knees $(23 \%)$ required further surgery not related to the allograft. Patients who were evaluated at follow-up and retained their grafts in situ had significant improvement in their function.

Patients with knee fracture are considered a challenging cohort due to high energy trauma, associated lesions, and a high potential of complications of further surgeries after open reduction and internal fixation. Furnes et $a l^{44}$ reported on the Norwegian Arthroplasty Register and analyzed early failures in total knee replacements, concluding that young age ( $<60$ years old) and sequelae after a fracture increased the risk for arthroplasty revisions due to infection, instability, and pain in comparison to primary gonarthrosis.

There are several limitations to the present study. First, we report on a case series with no control group. Second, one of our patient questionnaires, the modified Merle d'AubignéPostel (18-point) scale, has not been validated in the knee. However, it was the only instrument available for the early cases in this study, before other knee outcome instruments were widely available. The modified Merle d'AubignéPostel (18-point) provides information about pain, function, and range of motion, allowing comparison of patient outcomes over a long-term follow-up. Finally, another limitation is that not all of the outcome data could be recorded in routine clinical examinations in person. Some follow-up data were acquired by mail or telephone. In spite of these limitations, we believe the clinical data in this study reliably report outcome of this difficult to treat patient population.

We conclude that OCA transplantation is a useful salvage treatment option for osteochondral lesions caused by knee fracture. A high reoperation rate was observed, but successful outcome was associated with significant clinical improvement. Clinicians should consider OCA transplantation in young patients with symptomatic osteochondral defects after periarticular fractures in the knee.

\section{Acknowledgments and Funding}

The author(s) received no financial support for the research, authorship, and/or publication of this article.

\section{Authors' Note}

This study was approved by the Scripps Clinic Institutional Review Board and the work was done at Scripps Clinic and Scripps Green Hospital. 


\section{Declaration of Conflicting Interests}

The author(s) declared the following potential conflicts of interest with respect to the research, authorship, and/or publication of this article: Dr. Tirico is currently receiving payment for lectures from Sanofi. The remaining authors have no conflicts of interest to declare.

\section{Ethical Approval}

Ethical approval for this study was obtained from Scripps Institutionsl Review Board (APPROVAL NUMBER - IRB-136297/ID - IRB00004335).

\section{Informed Consent}

Written informed consent was obtained from all subjects before the study.

\section{References}

1. Lexer E. Substitution of whole or half joints from freshly amputated extremities by free plastic operations. Surg Gynecol Obstet. 1908;6:601-7.

2. Beaver RJ, Mahomed M, Backstein D, Davis A, Zukor DJ, Gross AE. Fresh osteochondral allografts for post-traumatic defects in the knee. A survivorship analysis. J Bone Joint Surg Br. 1992;74:105-10.

3. Gross AE, Silverstein EA, Falk J, Falk R, Langer F. The allotransplantation of partial joints in the treatment of osteoarthritis of the knee. Clin Orthop Relat Res. 1975;(108):7-14.

4. Bugbee W, Cavallo M, Giannini S. Osteochondral allograft transplantation in the knee. J Knee Surg. 2012;25(2):109-16.

5. Chu CR, Convery FR, Akeson WH, Meyers M, Amiel D. Articular cartilage transplantation. Clinical results in the knee. Clin Orthop Relat Res. 1999;(360):159-68.

6. Convery FR, Meyers MH, Akeson WH. Fresh osteochondral allografting of the femoral condyle. Clin Orthop Relat Res. 1991;(273):139-45.

7. Emmerson BC, Gortz S, Jamali AA, Chung C, Amiel D, Bugbee WD. Fresh osteochondral allografting in the treatment of osteochondritis dissecans of the femoral condyle. Am J Sports Med. 2007;35(6):907-14.

8. Garrett JC. Fresh osteochondral allografts for treatment of articular defects in osteochondritis dissecans of the lateral femoral condyle in adults. Clin Orthop Relat Res. 1994;(303):33-7.

9. Gortz S, De Young AJ, Bugbee WD. Fresh osteochondral allografting for steroid-associated osteonecrosis of the femoral condyles. Clin Orthop Relat Res. 2010;468(5):1269-78.

10. Jamali AA, Emmerson BC, Chung C, Convery FR, Bugbee WD. Fresh osteochondral allografts: results in the patellofemoral joint. Clin Orthop Relat Res. 2005;(437):176-85.

11. McCulloch PC, Kang RW, Sobhy MH, Hayden JK, Cole BJ. Prospective evaluation of prolonged fresh osteochondral allograft transplantation of the femoral condyle: minimum 2-year follow-up. Am J Sports Med. 2006;35(3):411-20.

12. Meyers MH. Orthopedics: osseous and osteochondral allografts. West J Med. 1987;146(4):469-70.

13. Shasha N, Aubin PP, Cheah HK, Davis AM, Agnidis Z, Gross AE. Long-term clinical experience with fresh osteochondral allografts for articular knee defects in high demand patients. Cell Tissue Bank. 2002;3(3):175-82.

14. Williams SK, Amiel D, Ball ST, Allen RT, Wong VW, Chen AC, et al. Prolonged storage effects on the articular cartilage of fresh human osteochondral allografts. J Bone Joint Surg Am. 2003;85(11):2111-20.

15. Asik M, Ciftci F, Sen C, Erdil M, Atalar A. The microfracture technique for the treatment of full-thickness articular cartilage lesions of the knee: midterm results. Arthroscopy. 2008;24(11):1214-20.

16. Bartha L, Vajda A, Duska Z, Rahmeh H, Hangody L. Autologous osteochondral mosaicplasty grafting. J Orthop Sports Phys Ther. 2006;36(10):739-50.

17. Minas T, Nehrer S. Current concepts in the treatment of articular cartilage defects. Orthopedics. 1997;20(6):525-38.

18. Farr J 2nd. Autologous chondrocyte implantation and anteromedialization in the treatment of patellofemoral chondrosis. Orthop Clin North Am. 2008;39(3):329-35.

19. Filardo G, Kon E, Di Martino A, Iacono F, Marcacci M. Arthroscopic second-generation autologous chondrocyte implantation: a prospective 7-year follow-up study. Am J Sports Med. 2011;39(10):2153-60.

20. Gobbi A, Kon E, Berruto M, Filardo G, Delcogliano M, Boldrini L, et al. Patellofemoral full-thickness chondral defects treated with second-generation autologous chondrocyte implantation: results at 5 years' follow-up. Am J Sports Med. 2009;37(6):1083-92.

21. Mandelbaum B, Browne JE, Fu F, Micheli LJ, Moseley JB Jr, Erggelet $\mathrm{C}$, et al. Treatment outcomes of autologous chondrocyte implantation for full-thickness articular cartilage defects of the trochlea. Am J Sports Med. 2007;35(6):915-21.

22. Minas T, Gomoll AH, Solhpour S, Rosenberger R, Probst C, Bryant T. Autologous chondrocyte implantation for joint preservation in patients with early osteoarthritis. Clin Orthop Relat Res. 2010;468(1):147-57.

23. Minas T, Gomoll AH, Rosenberger R, Royce RO, Bryant T. Increased failure rate of autologous chondrocyte implantation after previous treatment with marrow stimulation techniques. Am J Sports Med. 2009;37(5):902-8.

24. Nawaz SZ, Bentley G, Briggs TW, Carrington RW, Skinner JA, Gallagher KR, et al. Autologous chondrocyte implantation in the knee: mid-term to long-term results. J Bone Joint Surg Am. 2014;96(10):824-30.

25. Gracitelli GC, Meric G, Briggs DT, Pulido PA, McCauley JC, Belloti JC, et al. Fresh osteochondral allografts in the knee: comparison of primary transplantation versus transplantation after failure of previous subchondral marrow stimulation. Am J Sports Med. 2015;43(4):885-91.

26. Aubin PP, Cheah HK, Davis AM, Gross AE. Long-term follow-up of fresh femoral osteochondral allografts for posttraumatic knee defects. Clin Orthop Relat Res. 2001;(391 suppl):S318-27.

27. Gross AE, Kim W, Las Heras F, Backstein D, Safir O, Pritzker KPH. Fresh osteochondral allografts for posttraumatic knee defects: long-term follow-up. Clin Orthop Relat Res. 2008;466(8):1863-70.

28. Raz G, Safir OA, Backstein DJ, Lee PT, Gross AE. Distal femoral fresh osteochondral allografts: follow-up at a mean 
of twenty-two years. J Bone Joint Surg Am. 2014;96(13): 1101-7.

29. Shasha N, Krywulak S, Backstein D, Pressman A, Gross AE. Long-term follow-up of fresh tibial osteochondral allografts for failed tibial plateau fractures. J Bone Joint Surg Am. 2003;85(suppl 2):33-9.

30. Meric G, Gracitelli GC, Aram L, Swank M, Bugbee WD. Tibial slope is highly variable in patients undergoing primary total knee arthroplasty: analysis of 13,546 computed tomography scans. J Arthroplasty. 2015;30(7):1228-32.

31. Gracitelli GC, Meric G, Pulido PA, McCauley JC, Bugbee WD. Osteochondral allograft transplantation for knee lesions after failure of cartilage repair surgery. Cartilage. 2015;6(2):98-105.

32. American Association of Tissue Banks. Standards for tissue banking. 10th ed. McLean, VA: American Association of Tissue Banks; 2002.

33. Levy YD, Gortz S, Pulido PA, McCauley JC, Bugbee WD. Do fresh osteochondral allografts successfully treat femoral condyle lesions? Clin Orthop Relat Res. 2012;471(1):231-7.

34. Meric G, Gracitelli GC, Gortz S, De Young AJ, Bugbee WD. Fresh osteochondral allograft transplantation for bipolar reciprocal osteochondral lesions of the knee. Am J Sports Med. 2015;43(3):709-14.

35. Davidson PA, Rivenburgh DW, Dawson PE, Rozin R. Clinical, histologic, and radiographic outcomes of distal femoral resurfacing with hypothermically stored osteoarticular allografts. Am J Sports Med. 2007;35(7):1082-90.
36. Irrgang JJ, Anderson AF, Boland AL, Harner CD, Kurosaka $\mathrm{M}$, Neyret $\mathrm{P}$, et al. Development and validation of the international knee documentation committee subjective knee form. Am J Sports Med. 2001;29(5):600-13.

37. Insall J, Tria AJ, Scott WN. The total condylar knee prosthesis: the first 5 years. Clin Orthop Relat Res. 1979;(145):68-77.

38. Bugbee WD. Fresh osteochondral allografts. J Knee Surg. 2002;15(3):191-5.

39. Fitzpatrick PL, Morgan DA. Fresh osteochondral allografts: a 6-10-year review. Aust N Z J Surg. 1998;68(8):573-9.

40. Giannini S, Buda R, Ruffilli A, Pagliazzi G, Vannini F. Total femoral and tibial osteochondral allograft for remobilizing a knee after arthrodesis. Knee Surg Sports Traumatol Arthrosc. 2013;21(12):2784-9.

41. Meyers MH, Akeson W, Convery FR. Resurfacing of the knee with fresh osteochondral allograft. J Bone Joint Surg Am. 1989;71(5):704-13.

42. Gross AE, Shasha N, Aubin P. Long-term followup of the use of fresh osteochondral allografts for posttraumatic knee defects. Clin Orthop Relat Res. 2005;(435):79-87.

43. Getgood A, Gelber J, Gortz S, De Young A, Bugbee W. Combined osteochondral allograft and meniscal allograft transplantation: a survivorship analysis. Knee Surg Sports Traumatol Arthrosc. 2015;23(4):946-53.

44. Furnes O, Espehaug B, Lie SA, Vollset SE, Engesaeter LB, Havelin LI. Early failures among 7,174 primary total knee replacements: a follow-up study from the Norwegian Arthroplasty Register 1994-2000. Acta Orthop Scand. 2002;73(2):117-29. 